\title{
DIGITAL TRANSFORMATION IN BUSINESSES AND ITS DRIVERS
} İŞLETMELERDE DİJITAL DÖNÜŞÜM VE ETMENLERİ

\author{
Müge KLEİN ${ }^{1}$ \\ ${ }^{1}$ Doç. Dr., İşletme Bölümü, İktisadi ve İdari Bilimler Fakültesi, Türk-Alman Üniversitesi , İstanbul, Türkiye, klein@tau.edu.tr, ORCID: 0000-
} $0003-2341-2975$

\section{Article Info:}

Received : April 29, 2020

Revised : May 31, 2020

Accepted : June 6, 2020

\section{Keywords: \\ Digital Transformation \\ Digital Business \\ Digital Transformation Drivers \\ Digital Business Models \\ Anahtar Kelimeler: \\ Dijital Dönüsüm \\ Dijital Issletme \\ Dijital Dönüsüm Etmenleri \\ Dijital ISs Modelleri}

DOI: $10.46238 /$ jobda.729499

\begin{abstract}
In recent years, the digitalization starting with digitizing anolog data proceeding with digitalization of business processes is being replaced by digital transformation. In addition to business models getting value with personalized products, ecosystem partnerships formed by many different companies become widespread and increase the competition in the market. Digital transformation influence and transform the whole operation, organization and even the company culture of businesses. Digital transformation as a disruptive and complex process needs an integrative digital transformation strategy comprising all fields of businesses undergoing the transformation. The aim of this study is to determine those fields of businesses concerned with digital transformation and the drivers of business digital transformation by literature review and to develop a conceptual model displaying the cause and effect relationship among them, in order to support businesses by determining digital transformation scenarios and by developing suitable digital transformation strategies.
\end{abstract}

\section{ÖZET}

İşletmelerde analog verilerin sayısallaştırılmasıyla başlayan ve süreçlerin dijitalleşmesiyle devam eden dijitalleşme süreci, yerini son yıllarda dijital dönüşüm sürecine bırakmıştır. Kişiselleștirilmiş ürün sunmaya dayanan iş modellerinin yanında farklı işletmelerin dijital ortaklığıyla oluşan ekosistemler yaygınlaşmakta ve pazardaki rekabeti artırmaktadır. Dijital dönüşüm, işletmenin tüm işleyişini, organizasyon yapısını ve hatta şirket kültürünü bile etkilemekte ve dönüştürmektedir. Yıkıcı ve karmaşık bir süreç olan dijital dönüșüm, ișletmenin dönüșüm geçirecek tüm alanlarını kapsayan, bütünleyici genel bir dijital dönüşüm stratejisine ihtiyaç duyar. Bu çalışmanın amacı kaynak araştırması ile işletmelerde dijital dönüşüm yaşanacak alanları ve dönüşümü tetikleyen etmenleri belirlemek ve etmenler ve alanlar arasındaki neden-sonuç ilişkisini gösteren kavramsal bir model geliştirerek işletmelerin dijital dönüşüm senaryoları belirlemesini ve bunlara uygun stratejiler geliştirmesini desteklemektir.

(C) 2020 JOBDA All rights reserved

\section{1| GíRiş}

İçinde bulunduğumuz dördüncü Sanayi Devrimi'ni ifade eden Endüstri 4.0 kavramı ile ortaya çıkan ve gerek ekonomik alanları gerekse kamusal ve toplumsal alanların yanında kişisel hayatları da etkileyen bir dijital dönüşüm gündemdedir (Klein, 2019a; Schwab, 2017). Özellikle geride bıraktığımız son on sene içinde ağ teknolojilerinin, cep telefonlarının, sosyal medyanın ağırlıklı kullanılmasının yanında Nesnelerin İnterneti, Bulut Bilişim, Artırılmış Gerçeklik, Büyük Veri Analizi gibi 
yeni dijital teknolojilerin ve yöntemlerin de ortaya çıkmasıyla aslen 70li yıllarda bilgisayarların gelişmesiyle başlayan dijitalleşme, günümüzde dijital dönüşüm adı altında farklı bir boyuta taşınmıştır.

Yeni dijital teknolojilerle hızla ilerleyen dijital dönüşüm, ekonomik şartları ve beklentileri de değiștirmektedir. Zamandan ve yerden bağımsız her türlü veriye erișim olanağı, fiziksel ürünün değil, verilerin ve hizmetlerin ön planda olduğu bir ticaret ortamında ekonominin büyümesi ve verimliliğin artması beklentisini beraberinde getirmektedir (Schwab, 2017). Mevcut iş modelleri dijitalleşerek dönüşmekte, yeni iş modelleri doğmakta ve bunun sonucunda ișletmelerin iș değer zincirleri ve organizasyonları farklı yapılar gerektirmektedir. Ancak farklı dijital teknolojileri üretebilen, kullanabilen veya farklı şekilde pazarlayabilen işletmeler yeni ekonomik şartlara uyum sağlayabilecekleri ve yeni zorlu rekabet ortamındaki dijital pazarda hayatta kalabileceklerinden dolayı dijital dünyaya adaptasyon ve uyum süreci büyük önem taşımaktadır (Schwab, 2017).

İșletmelerin dijital dönüșümü, birliği bozan, yıkıcı bir süreçtir ve bundan dolayı karar verici merciler tarafından stratejik olarak yönetilmelidir (Berghaus \& Back, 2016; Besson \& Rowe, 2012; Hess, Matt, Benlian, \& Wiesböck, 2016). Dijital dönüşüm stratejilerini belirlerken bir dijital dönüşüm yol haritası hazırlamakta zorlanan işletmelerin, işletmenin dönüşümden etkilenecek her alanının dikkate alındığı bütüncül bir yaklaşıma ihtiyacı vardır (Fitzgerald, Kruschwitz, Bonnet, \& Welch, 2014). Dijital dönüşüm olgusunun, özeliklerinin, tetikleyici etmenlerinin vs. belirlenmesi, dijital dönüşümün sebep ve sonuçlarının eşleşmesi ve tanımlanması günümüzde sosyal bilimler alanında bir araştırma boşluğudur (Morakanyane, Grace, \& O'Reilly, 2017; Pflaum \& Schulz, 2018). Bu konuda hakkında yapılmış az sayıdaki çalışmada da, Morakanye vd. (2017)'nin çalışması örneğindeki gibi dijital dönüşümün etmenleri, sonuçları ve dijital dönüşüm yaşanacak alanlar belirlense de etmenler ve alanlar arasında bağlantı kurulmamaktadır.

$\mathrm{Bu}$ çalışmanın amacı işletmelere dijital dönüşüm stratejileri belirlemekte yardımcı olabilmek için dijital dönüşümü tetikleyen farklı etmenleri ve bu etmenlerin işletmenin hangi alanında bir dijital dönüşüme yol açacağını belirlemektir. Çalışmanın araştırma soruları şu şekilde sıralanabilir: İşletmelerde dijital dönüşüm hangi alanlarda yaşanır? $\mathrm{Bu}$ alanlardaki dijital dönüşümü tetikleyen etmenler nelerdir? Dijital dönüşüm yaşanacak alanlar ve dönüşümü tetikleyen etmenler arasında nasıl bir ilişki vardır? Araştırma yöntemi olarak kaynak araştırmasına ve kavramsal modellemeye dayanan bu çalışma teorik bir çalışmadır. Bu bağlamda kaynak araştırması ışığında işletmelerdeki dijital dönüşüm incelenerek işletmelerdeki farklı dijital dönüşüm alanları ve dijital dönüşümü tetikleyen etmenler belirlenecek ve bu etmenler ve dijital dönüşüm alanları arasındaki sebep-sonuç iliş̧kisini gösteren nedensel bir model geliștirilecektir.

Çalış̧manın ikinci bölümünde işletmelerde Endüstri 4.0 ile gündeme gelen dijital dönüşümden bahsedilerek işletmelerde dijital dönüşüm yaşanacak alanlar, üçüncü bölümde ise kaynak araştırmasına dayanarak işletmelerde dijital dönüşümü tetikleyen etmenler belirlenecektir. Daha sonraki bölümde dijital dönüşüm alanları ve etmenleri arasındaki bağlantı, ilişkiler diyagramı yöntemiyle modellenerek, bunu gösteren nedensel model tanıtılacaktır. Son bölümde bu modelin ilerideki araştırmalara nasıl destek olabileceği gösterilerek çalışma sonlandırılacaktır.

\section{2 | İŞLETMELERDE DIJITAL DÖNÜŞÜM VE ALANLARI}

Dijital dönüşüm hakkındaki kaynaklar incelendiğinde Dijital Dönüşümün özellikle son beş yılda Endüstri 4.0 konsepti ile ortaya çıkmış bir kavram olduğu görülmektedir. Fakat aslında işletmelerde dijital dönüşüm, dijital teknolojilerin işletme içinde kullanılması ile diğer bir deyişle dijitalleşme süreciyle başlamıştır (Klein, 2019a). Günümüzde yeni dijital teknolojiler özellikle işletmelerin üretim süreçlerini etkilemekte ve dönüştürmektedir. Robotların, sensörlerin ve otonom sistemlerin hâkim olduğu akıllı fabrikalar, işletmelerin üretim süreçlerinde dijital dönüşüme yol açmaktadır. Dijital dönüşüm, sadece üretim süreçlerinin değişmesi anlamına gelmediği gibi çeşitli işletme fonksiyonlarında bilgisayar veya İnternet kullanımından öteye geçerek Sosyal Medya, Yapay Zekâ, Büyük Veri gibi yeni dijital teknolojilerin işletme süreçlerinde kullanılması ve bunun sonucunda yeni iş modellerinin geliştirilmesini ifade eder. İşletmelerdeki dijital dönüşüm hakkında literatürde farklı tanımlara rastlanmaktadır. Örneğin işletmelerde dijital dönüşüm, yeni dijital teknolojilerin (Sosyal Medya, Büyük Veri Analizi, Bulut Bilişim vb.) işletmeyi iyileștirilmek için kullanılması anlamına gelir (Fitzgerald, vd. 2014). Başka bir tanıma göre dijital dönüşüm, dijital teknolojilerin ve yetkinliklerin gücüyle değer oluşturmak amaciyla yeni iş modelleri, işletme süreçleri ve müşteri deneyimini mümkün kllan evrimsel bir süreçtir (Morakanyane, vd. 2017).

İşletmelerde dijital dönüşüm denince akla ilk gelen dönüșüm alanı iş modellerinin dönüșmesidir. Ancak işletmelerdeki dijital dönüşümü sadece iş modellerindeki değișiklik olarak görmek yeterli olmaz, çünkü dijital dönüşüm işletmeleri bütün olarak etkileyen ve işletmelerin organizasyon yapılarında, şirket kültüründe, çalışma yerlerinde ve hatta iş etiği anlayışında bile gerçekleşen bir durumdur (Henriette, Feki, \& Boughzala, 2016). Kaynaklara göre işletmelerde dijital dönüşüm, 
ürünler, hizmetler, müşteri deneyimi, iş değer zincirleri, iş süreçleri gibi alanlarda olur (LiereNetheler, vd. 2018; Markides, 2006; Matt, vd. 2015; Westerman, vd. 2011). Yeni dijital teknolojiler sayesinde işletmeler sadece ürünlerini ve iş modellerini dijitalleştirmekle kalmaz, süreçlerini de dijitalleştirerek yeni iş modellerine adapte olurlar (Burmeister, vd. 2016). Tüm bilgilere dayanılarak işletmelerin dijital dönüşüm yaşadığı alanlar bu çalışmada üç başlık altında toplanır:

- İș Modelleri

- İş Süreçleri

- Organizasyon

Dijital dönüşüm sonucunda ortaya çıkan yeni işletme görünümüne dördüncü sanayi devriminin etkisinden esinlenerek İşletme 4.0 ismi verilir. İşletme 4.0 yeni dijital teknolojileri uygulayan ve iş süreçlerini; organizasyon yapısını ve iș modellerini dönüștürerek değişen pazar şartlarına adapte olabilen bir işletmedir (Şekil 1).

\section{Şekil 1. Dijital Dönüşüm - İşletme 4.0}

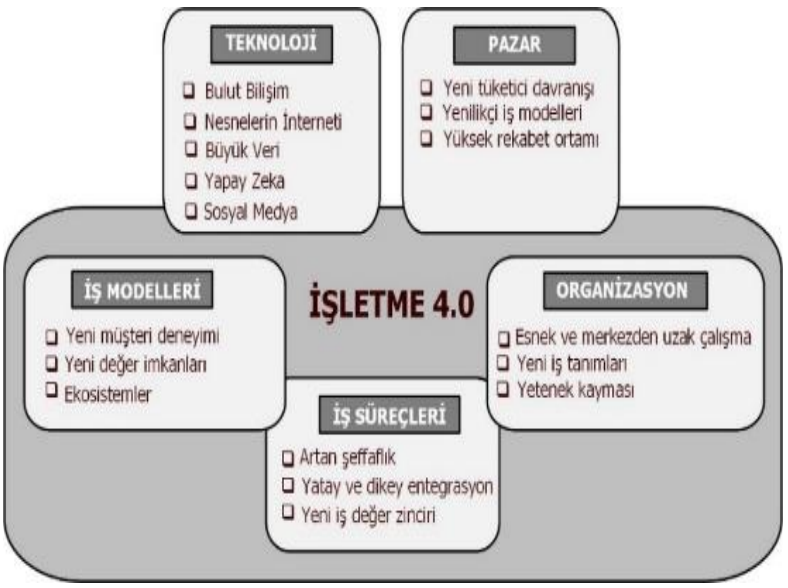

Kaynak: Yazar

\section{1 | İşletmelerde Dijital Dönüşüm ve Alanları}

Dünya üzerindeki milyonlarca bilgisayarı birbirine bağlayan İnternet ve kablosuz ağ teknolojileri, insanlar arasında yer ve zamandan bağımsız iletişim ve etkileşimi destekler ve yer ve zamandan bağımsız veriye erişimi mümkün kılar. Bulut Bilișim teknolojisi, verileri, yazılımı ve onlara erişmek için gerekli cihazları tamamen birbirinden ayıran bir yaklaşıma sahiptir (Klein, 2019a). Bulut Bilişim sayesinde işletmeler her türlü veriye ve yazılıma, yer ve zamandan bağımsız olarak ağ üzerinden hızlıca erişilebilir. $\mathrm{Bu}$ veriler farklı kaynaklardan gelen ve sürekli değişen üretim verileri, ürün verileri, satış verileri, müşteri verileri veya çalışan verileri gibi işletmeyi ilgilendiren her türlü veri olabilir. Büyük Veri adı verilen bu karmaşık veri kümesini analiz etmek ve işletmelere doğru karar vermede son derece önemli yönlendirmelerde bulunmak amacıyla son yıllarda veri analiz yöntemleri geliştirilmiștir
(Banger, 2018). Veri analiz yöntemleri işletmelerdeki tüm verileri birleștirerek bilgileri ve bu bilgileri birleştirerek özellikle kişiselleştirilmiş ürün ve hizmetler geliştirilmesinde ve risk analizinde kullanılacak bilgi dağarcığını oluşturmayı hedefler. Nesnelerin İnterneti her türlü cihaza veya objeye gömülen sensörler aracılığıyla veri toplanmasına dayanır (Özdoğan, 2017). Toplanan veriler ağ üzerinde paylaşılır ve yönetilir. Son yıllarda en çok gelişmiş dijital teknolojilerden bir diğeri de, otonom araçlar veya otonom robotlar gibi akıllı makineler ile gündeme gelen Yapay Zekâ uygulamalarıdır. İşletmelerin özellikle üretim faaliyetlerinde kullanılan, insanların davranışlarını taklit etmeye programlanmış ve insanlardan bağımsız eyleme geçen akıllı makineler iş süreçlerini kolaylaştırır ve hızlandırır. Bunların yanında Sosyal Medya uygulamaları kullanıcılar arasındaki bilgi paylaşımını ve işbirliğini destekleyen yazlımlardır. İşletmeler, mobil cihazlar ile kolayca erişim sağlanan sosyal medya yazılımlarını özellikle müşteri yönetiminde kullanırlar (Klein, 2019b). Klein'a (2019a) göre yeni gelişen dijital teknolojilerin farklı kombinasyonları işletmelerde farklı uygulamaların geliştirilmesini mümkün kılmaktadır. Örneğin, üretimde Nesnelerin İnterneti, Yapay Zekâ ve Bulut Bilişim teknolojilerinin ortak çalışması sonucu fabrikalarda Siber Fiziksel Sistemler ortaya çıkmıştır. Veya İnternet alışveriş sitelerindeki Sosyal Ticaret, Sosyal Medya ve Büyük Veri teknolojilerinin entegrasyonudur.

\section{2 | Yeni Pazar Şartları}

Yer ve zamandan bağımsız her türlü veriye ulaşabilme kolaylığı, pazardaki fiyatlar ve ürünler hakkındaki şeffaflı̆̆ı artırmaktadır. Bu durum bir yandan pazardaki işletmeler için yüksek bir rekabet ortamı yaratırken (Schwab, 2017), diğer bir yandan da yeni bir tüketici davranışına sebebiyet vermektedir. Müşterilerin taleplerini karşılamak veya yeni müşteriler elde edebilmek için yenilikçi iş modelleri ortaya çıkmaktadır. Müşteri odaklı iş modelleri geliştiren işletmeler müşterilerin paylaştıkları verilerin gerçek zamanlı analizini yapmakta ve buna göre yerden ve zamandan bağımsız olarak müşterilerine hizmet sunmaktadır (Schwab, 2017). Şeffaflığın süregeldiği ve müșterinin kolaylıkla alternatif başka bir ürüne veya markaya kayabildiği bir ortamda marka değeri zor kazanılan ve kolay kaybedilen bir ödül olmaktadır (Schwab, 2017). Bunun yanında dijital yetkinlikleri ve tecrübeleri yüksek olan müşterilerin, ürünlerden yüksek deneyimsel beklentileri olmakta ve daha çabuk, daha ucuz ve daha kaliteli ürünler talep etmektedirler.

Schwab'a (2017) göre dijital dönüșümü bașarıyla tamamlamış işletmeler daha kaliteli ve daha ucuz ürünleri müşteriye daha hızlı ulaştırabilen işletmeler olacaktır. Pazarda oluşan yeni rakipler sadece startup şirketleri değil yıllardan beri klasik anlamda iş 
değeri üreten ama dijital dönüşümü başarıyla gerçekleştiren işletmeler de olabilir.

Bunun yanı sıra üretimde akıllı sistemlerin kullanılmasıyla maliyetlerin düşmesi ve verimliliğin artması beklenmektedir. Müşterilerin de üretim sürecine dahil olması ürün geliștirme maliyetini düşürecek ve ürünlerin pazara daha çabuk çıkmasını sağlayacaktır (Blunck \& Werthmann, 2017). Bu sayede arz ve talep arasındaki fark en aza indirgenecek, aşırı üretim azalacaktır.

\section{3 | Yeni İș Modelleri}

İş modeli bir işletmenin nasıl değer ürettiğini, bu değeri tüketiciye nasıl dağıttığını ve bu değerle nasıl gelir elde ettiğini gösterir (Osterwalder, Pigneur, Oliveira \& Ferreira, vd. 2011). Dijital dönüşüm, iş modellerinin hem değer üretiliş ve dağıtım şeklini hem de gelir elde etme șeklini değiștirir (Blunck \& Werthmann, 2017). Bir iș modelinin dijital iș modeli olarak adlandırılabilmesi için dijital teknolojilerdeki değişikliklerin işletmenin iş yapış ve gelir üretme şeklini kökten değiştirmesi gereklidir (Veit, vd. 2014). Diğer bir tanıma göre yeni iş modelleri, dijital teknolojilerin sağladığı potansiyeli ekonomik değere çeviren iş modelleridir (Ehret \& Wirtz, 2017).

Öncelikle İnternet'in daha sonra Sosyal Medya'nın ve en son olarak da Nesnelerin İnterneti teknolojisinin kullanılmasıyla yeni iş modelleri oluşmuş ve oluşmaya devam etmektedir (Fleisch, vd. 2015). Buna göre Fleisch vd. (2015) dijital teknolojilerin etkisiyle iş modellerinin gelişimini üç evrede izlemektedir (Şekil 2):

- İnternet etkisiyle olușan iș modelleri

- Sosyal Medya etkisiyle oluşan iş modelleri

- Nesnelerin İnterneti etkisiyle oluşan iş modelleri

Şekil 1. Dijital İş Modelleri

\begin{tabular}{|c|c|c|}
\hline $\begin{array}{r}\text { İnternet } \\
\text { (Web 1.0) } \\
\text { - E-Ticaret }\end{array}$ & \begin{aligned} & \multicolumn{1}{c}{ Sosyal Medya } \\
&$($ Web 2.0) \\
& - Crowdsourcing \\
& - Long Tail \\
& - Platform modelleri \end{aligned} & $\begin{array}{l}\text { Nesnelerin Interneti } \\
\text { (Endüstri 4.0) } \\
\text { - Akıllı ürün } \\
\text { - Akıllı servis } \\
\text { - Kiralama } \\
\text { - Ortakllk }\end{array}$ \\
\hline
\end{tabular}

Kaynak: Fleisch, E., Weinberger, M., \& Wortmann, F. (2015). Geschäftsmodelle im internet der dinge. Schmalenbachs Zeitschrift für betriebswirtschaftliche Forschung, 67(4), 444-465.

İnternet'in gelişmesiyle çevrimiçi ticaret mantığına dayanan Elektronik Ticaret iş modelleri gelişmiştir. ETicaret, ürün veya hizmetlerin ticaretinin çevrimiçi veri gönderiminin sağlandı̆̆ İnternet ortamında elektronik mali sistemler kullanılarak yapılmasıdır (Wigand 1997). Kullanıcının aktif olarak içerik geliştirmesine imkan sağlayan Web 2.0 - İnternet teknolojisi, Elektronik Ticareti sosyal medya ortamına taşıyarak müşteri odaklı ürün geliştirmeye dayalı Sosyal Ticaret olgusunu geliştirmiștir (Liang \& Turban, 2011). Sosyal Ticaret iş modelleri crowdsourcing (kitlesel kaynak kullanımı), longtail (uzun kuyruk teorisi) gibi prensiplerden faydalanan iş modellerinin yanında dijital platformlara dayalı iş modellerinden oluşur (Klein, 2019b). Kolektif zekanın bireysel zekadan daha iyi çözümler üretmesi düşüncesine dayanan crowdsourcing iș modelleri, müşterilerin, ağ içerisinde işletmelerin ürün geliştirme sürecine dahil olmalarını hedefler (Bächle, 2016). Ekonomideki longtail teorisi Sosyal Ticaret kapsamında dijital teknolojiler sayesinde kitlesel pazarları birçok küçük niş pazara çevirerek az talep gören niş ürünlerin belirlenmesini ve satışını mümkün kılan iş modelleri olarak kendini gösterir (Klein, 2019b). İșletmelerin kendi ürünlerini veya birçok farklı satıcının ürününü pazarladığı çevrimiçi mağaza platformları ve ürün bazlı tavsiye platformları da Sosyal Ticaret kapsamında yaygınlaşmış iş modelleridir. 90'lı yılların sonunda oluşan dotcom Elektronik Ticaret şirketleri yerini Nesnelerin İnterneti teknolojisiyle platform üzerinde, işbirliğinden oluşan, veriye dayanan ve hizmetin değer olarak sunulduğu iş modellerine bırakmaktadır (Burmeister vd., 2016). Günümüzde geleneksel şirketlerin iş modelleri bu tür yenilikçi iş modelleri karşısında tehdit altındadır. Endüstri 4.0 ile gündeme gelen Nesnelerin İnterneti teknolojisinin dijital dönüşüm sonucunda beraberinde getirdiği çeşitli yenilikçi iş modelleri vardır. Dijital dönüşüm ile işletmeler, akıllı ürünlerin ve hizmetlerin pazarlamasına dayalı, gerçek zamanlı, kiralama ve ortaklık iş modellerine geçmektedirler. Yenilikçi iş modelleri aşağıdaki şekilde gruplandırılabilir (Matyssek, 2017):

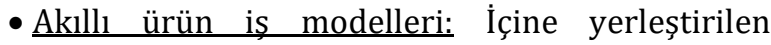
sensörler sayesinde dijital yetenekli sayılan akıllı ürünler bu tür iş modellerinde değer oluşturur. Ürünlerin akıllı olması onların izlenebilir ve çift yönlü iletişime açık olması gibi faydalar sağlar. Akıllı ürünler sayesinde işletmeler, ürünü satın alan müşterileriyle satış sonrası uzun vadeli iletişim halinde kalabilir ve ürün kullanımı hakkında bilgi edinebilirler.

- Akıllı hizmet iș modelleri: Akıllı ürünlerin hizmetler ile birleștirildiği kombinasyon iş modelleridir. Akıllı üründen elde edilen verilere göre müşteriye uygun hizmet verilmesine dayanır.

- Kiralama is modelleri (pay per use): Ürünün satılmadığı, sadece ürün kullanımının ücretlendirildiği iş modelleridir. Müşterinin ürünü kullanım şekline veya zamanına göre uygun ödeme yapması kiralama iş modelinde mümkündür. 
- Ortaklık is modelleri: Farklı branșlardan farklı şirketlerin ortaklıklarının ön planda olduğu ve işletmeler arasındaki işbirliğinin her işbirlikçiye ayrı fayda sağladığı yenilikçi platform iş modelleridir. Arz ve talep taraflarının dijital bir platform üzerinde bir araya geldiği ortaklık iş modelleri, işletmeler, işletmenin paydaşları ve müşteriler arasında "ekosistemler" gelişmesine dayanır. İşletme ekosistemleri fikri yeni değildir ve akademik çalıșmalarda uzun yıllardan beri biyolojik ekosistemlere benzetilerek bu tür ekosistemlerin bahsi geçmektedir (Peltoniemi \& Vuori, 2004; Kress vd., 2017).

\section{4 | Yeni İş Süreçleri}

Porter (2001), işletmelerdeki iș süreçlerini temel faaliyetler ve destekleyici faaliyetler olarak iki grupta ele alır (Şekil 3). Temel faaliyetler, üretim için gerekli hammaddelerin satın alınmasından ürünlerin üretilmesine, üretimden satışa ve satıştan ürün servisine kadar tüm mal ve hizmet akışını ifade eden iş değer zincirini kapsar. Destekleyici faaliyetler ise işletmedeki finans, muhasebe, yönetim, insan kaynakları gibi diğer birimler ve fonksiyonlar ile iş değer zinciri arasındaki işlevlerden oluşur.

\section{Şekil 2. İş Süreçleri}

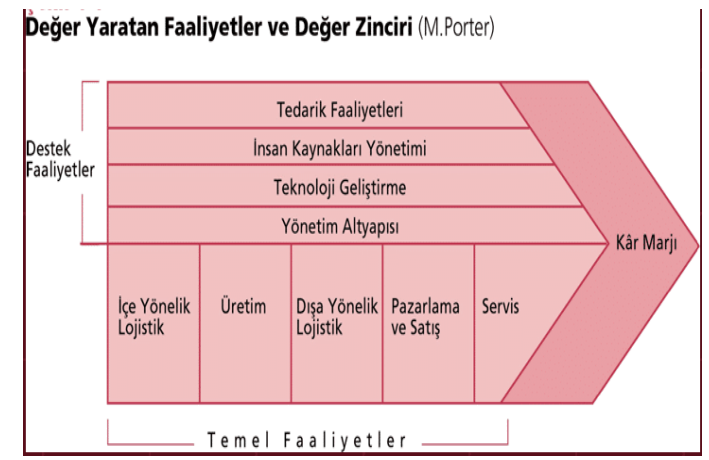

Kaynak: https://www.sezginkoyun.com/isletmeanalizi/\#

İşletme 4.0 kapsamında kullanılan dijital teknolojiler iş süreçlerini yakından etkilemektedir. Özellikle üretimde yeni dijital teknolojilerin kullanılması iş değer zincirinin ilk halkasından son halkasına kadar işleyişi değiştirmekte ve klasik, iç ve dış sınırları belli iş değer zinciri anlayışını kaldırmaktadır (Blunck \& Werthmann, 2017). Bugüne kadar kağıt tabanlı ve bilgisayar destekli yürütülen süreçlerden oluşan iş değer zinciri bu geleneksel hibrit sistemin ötesine geçilerek komple bir dijital sistem entegrasyonu olarak yürütülür (Akben \& Avşar, 2017). Gerçek zamanlı ve şeffaf veri akışı sayesinde iş değer zinciri üzerindeki tedarikçiler, üretici işletme, işletmenin tüm faaliyetleri ve müşteriler birbirine bağlanmaktadır. Bu durum iş süreçlerindeki yatay ve dikey entegrasyon olarak adlandırılır. Yatay entegrasyon iş değer zincirini oluşturan temel faaliyetlerin başında bulunan tedarikçiler ve sonunda bulunan müșterilerin de iş değer zincirine katılması ve tüm bilgi akışının müşteriden tedarikçiye doğru aktığı bir süreç yapısına gelinmesidir (Blunck \& Werthmann, 2017). Dikey entegrasyon, iş değer zincirindeki temel faaliyetlerin işletmelerin tüm destekleyici faaliyetleri ile birleşmesiyle aralarında bilgi alışverişinin sağlanmasıdır (Blunck \& Werthmann, 2017). Yatay ve dikey entegrasyon sayesinde işletmeler, tedarikçiler veya müşteriler tarafından talep edilen değişikliklere daha çabuk cevap verebilecek esnek ve çevik bir işleyişe sahip olurlar (Blunck \& Werthmann, 2017).

\section{5 | Yeni Organizasyon Yapısı}

Dijital dönüşümün etkilediği en önemli işletme alanlarından biri de işletmedeki organizasyon yapısıdır. Değișen iş süreçlerine uyum sağlamak için işletmelerdeki hiyerarşik organizasyon yapılarının yerlerini, hiyerarşik açıdan daha düz, ağ şeklinde, işbirliğine dayanan ve kendini duruma göre organize eden esnek yapılara bırakması beklenmektedir (Kofler, 2018; Schwab, 2017). İşletmenin organizasyon yapısı şirket çalışanlarının kısa zamanda ve ait oldukları bölümden bağımsız şekilde birbirleriyle ortak çalışmalarını mümkün kılan esnek ve dağınık bir şekle dönüşmektedir. Yeni organizasyon yapısında yetenek kaymaları yaşanacak ve bu da yeni iş tanımlarını beraberinde getirecektir. Ayrıca çalışanların başarı ölçümü ve motivasyonu farklı şekillerde olacak ve işletmenin başarısının anahtar noktalarından birisini teşkil edecektir (Schwab, 2017). Bunun yanı sira yeni organizasyon yapısını yönetecek liderlerin de farklı becerilere ve yönetim şekillerine ihtiyacı olacaktır (Klein, 2020). Dijital dönüşüm esnasında işletmeler yeni iş modelleri geliştirirken mevcut iş modellerinin bazılarını dönüştürmekte bazılarını da korumakta ve hatta iyileştirmektedir. Bu da iki farklı organizasyon yapısının aynı anda işler durumda olması sonucunu doğurur. Staffen \& Schoenwald (2016) tarafından "iki elini kullanabilme" yeteneği olarak adlandırılan bu durum iki farklı organizasyon yapısı arasındaki dengeyi sağlamak için gerekli esneklik ve çevikliği ifade eder ve yöneticilerin de bu tür yeteneklere sahip olan bir lidere dönüşmelerini gerektirir.

\section{3 | İşletmelerde Dijital Dönüşümü Tetikleyen Etmenler}

Dijital dönüşüm işletmelerde yıkıcı bir değişikliğe sebep verdiği için işletmelerin tüm dijital dönüşüm sürecini planlayan, yürüten, kontrol eden ve başarısını ölçen, bütüncül bir dijital dönüșüm stratejisine ihtiyacı vardır (Kofler, 2018). Dijital dönüşüm stratejisini belirlerken dönüşümü tetikleyen etmenler arasındaki sebep-sonuç ilişkisini belirlemek önem taşır (Liere-Netheler vd., 2018). Bu 
çalışmada dijital dönüşüm etmenleri iki aşamalı bir yol izlenerek belirlenmiștir:

- Kaynak araştırması: Kaynaklarda bahsi geçen dijital dönüşüm etmenlerini tespit etmek.

- Gruplandırma: Tespit edilen dijital dönüşüm etmenleri arasındaki sebep-sonuç veya kapsam gibi ilișkilere göre etmenleri aralarında gruplandirmak.

İşletmelerdeki dijital dönüşüm hakkında yapılan kaynak araştırmasında dijital dönüşümü tetikleyen etmenler aranmıştır. Bazı kaynaklar işletmelerdeki dijital dönüşümü genel olarak ele alırken (Chanias, 2017; Ezeokoli vd., 2016; Kane vd., 2015; Kofler, 2018; Liere-Netheler vd., 2018; Morakanye vd., 2017; Pflaum \& Schulz, 2018; Tesch \& Brillinger, 2017; Verina \& Titko, 2019), bazıları sadece iş modellerinin dönüşümü olarak görmektedir (Anderson \& Kupp, 2008; Burmeister vd., 2016; Chesbrough, 2010; de Reuver \& Bouwman, 2009; Foss \& Saebi, 2017; Wirtz \& Daiser, 2017).

İş modellerinin dönüşümünü inceleyen kaynakların bir kısmı doğrudan dijital dönüşüm sonucu tetiklenen iș modellerinin dönüșümünü incelemekte (Burmeister vd., 2016; de Reuver \& Bouwman, 2009; Foss \& Saebi, 2017) bir kısmı da konuya iş model inovasyonu olarak daha genel yaklaşmaktadır (Anderson \& Kupp, 2008; Chesbrough, 2010; Wirtz \& Daiser, 2017). İş model yeniliklerini tetikleyen etmenlerin üzerinde az araştırma yapılmış bir konu olduğuna vurgu yapan Wirtz \& Daiser (2017), ortaya koydukları kavramsal çerçevede iş model yeniliğini etkileyen etmenleri mikro ve makro seviyede gruplandırmakta ve mikro seviyedeki etmenleri, değişen müşteri beklentileri, rekabet, şirket dinamikleri, ürün ve hizmet yenilikleri olarak, makro etmenleri ise globalleşme, teknoloji, mevzuata ilişkin ekonomik konular ve pazar kaymaları olarak belirlemektedir. Diğer bir çalışmada iş modellerinde yenilik yaratan etmenler olarak iş değer zincirlerinin rekonfigürasyonu, geleneksel olmayan ortaklarla işbirliği ve en önemlisi olarak pazardaki rekabet sıralanmıştır (Anderson \& Kupp, 2008). Chesbrough (2010) ise çalışmasında örgütsel liderliğin iş model inovasyonundaki etkisine dikkat çekmektedir. Diğer bir çalışmada işletmenin iş model dönüşümünü tetikleyen etmenler olarak yeni teknolojik olanaklar, değişen müşteri ihtiyaçları ve işlevleri iyileştirme isteği kabul edilmektedir (Burmeister vd., 2016). İș modellerinin dönüşümünü etkileyen dış etmenleri inceleyen bir diğer çalışma en önemli etmen gruplarının teknoloji, pazar ve devletin yaptığı düzenlemeler olduğunu ortaya koymuştur (de Reuver \& Bouwman, 2009).

İşletmelerdeki dijital dönüşümü tetikleyen etmenler bazı kaynaklarda genel olarak incelenmiştir: Örneğin
Ezeokoli vd. (2016) beş farklı kaynaktan topladığı bilgiler ışığında işletmelerdeki dijital dönüşüm etmenlerini kârlılık ve yeni gelir artışı elde etmek, müşterilerin dijital beklentileri değiştiği için müșteri memnuniyetini sağlamak, işlevsel verimliliği artırmak, işletmenin pazardaki değişikliklere uyumunu hızlandırmak ve devamlı değișen pazar yapısında işletmeye rekabet avantajı sağlamak olarak sıralamıştır. 2014 yılında 129 farklı ülkedeki çeşitli branștan 4800 şirket çalışanı ile yapılan anket çalışması sonucuna göre işletmelerdeki dijital dönüşüm sadece dijital teknolojilerin ve şirketteki dijital yetkinliklerin tetiklediği bir olgu değildir; dijital dönüșümün diğer bir önemli etmeni liderlerin aldığ Morakanye vd. (2017) dijital dönüşüm etmenleri olarak dijital teknolojileri, şirket çalışanlarının dijital yetkinliklerini, şirkette alınan stratejik kararları ve pazardaki yeni iş modellerini göstermektedir. Farklı bir çalışmada dijital dönüşüm etmenleri, yeni pazarların ve yeni iş olanaklarının ortaya çıkması, artan rekabet, müşterilerin ihtiyaçları ve artan istekleri, teknolojik gelişimler, görev ve süreçlerin dijitalleşmesi, üst yönetim desteği ve liderlerin dijital dönüşümün önemini fark etmeleri olarak belirlenmiștir (Verina \& Titko, 2019). Kofler (2018) çalışmasında dijital dönüşümü tetikleyen kuvvetler olarak müşterilerin ve diğer paydaşların beklentilerini, dijital teknolojileri, yeni dijital iş modellerini ve rakiplerin faaliyetlerini saymıştır. Tesch \& Brillinger'e (2017) göre hızlı teknolojik değişimler, artan rekabet ve dinamik değişen pazar gibi diş etmenler işletmelerde yeni iş modellerinin oluşmasını tetikler.

Bazı çalışmalarda dijital dönüşümü tetikleyen etmenler dış ve iç olarak iki gruba ayrılmıştır. Örneğin bir çalışmada yeni dijital teknolojiler dış etmen, işletmedeki yeni stratejik kararlar ise dijital dönüşümün iç etmeni olarak görülmüştür (Pflaum \& Schulz, 2018). Foss \& Saebi (2017) çalışmasında iş modellerini dönüştüren dış etmenler olarak rekabette değişiklik, yeni teknolojiler, yeni ağ pozisyonu ve dıș paydaşların taleplerini, iç etmenler olarak ise dijital yetkinlikler ve işletmenin stratejik değişiklik kararlarını sıralamıştır. Benzer şekilde Liere-Netheler vd. (2018) çalışmasında dijital dönüşüm etmenlerini örgütsel ve dış etmenler olarak iki grupta toplamıştır. Örgütsel etmenler süreç iyileştirmesi, iş yeri iyileştirmesi, yatay ve dikey entegrasyon, yönetime destek, maliyet düşürülmesi olarak belirlenmekte; dış etmenler ise müșteri talepleri, iș değer zinciri, yenilik baskısı, pazar baskısı ve devletin uyguladığı yeni mevzuatlardır. Chanias'a (2017) göre işletmelerdeki dijital dönüşümü tetikleyen iki önemli dış faktör gelişen dijital teknolojiler sonucunda değișen müşteri tercihleri ve beklentileridir. İç tetikleyici ise kârı arttırmak ve üst 
yönetimin yeni gelir kaynakları keşfetmek isteği ve dijital dönüşüm ile ilgili aldığı stratejik kararlardır.

Kaynak araştırması sonucu işletmelerdeki dijital dönüşümü tetikleyen etmenler şu şekilde belirlenmiștir (Tablo 1):

- Dijital teknoloji

- Dijital yetkinlik

- Stratejik karar
- İșlevsel iyileștirme

- Üst yönetim

- Kâr ve gelir artışı

- İş değer zinciri

- Mevzuat

- Yeni işbirlikleri

- Rekabet avantajı

- Müşteri memnuniyeti

- Pazara ve iș modellerine uyum

Tablo 1. Dijital Dönüşüm Etmenleri

\begin{tabular}{|c|c|c|c|c|c|c|c|c|c|c|c|c|}
\hline & 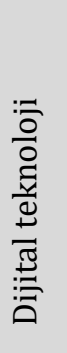 & 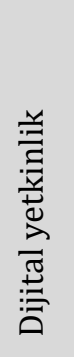 & 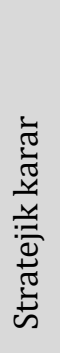 & 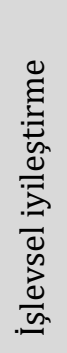 & 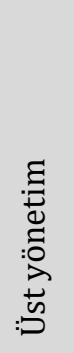 & 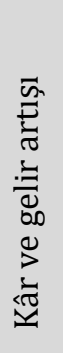 & 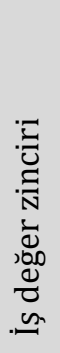 & $\begin{array}{l}\frac{N}{\pi} \\
\stackrel{N}{N} \\
\sum\end{array}$ & 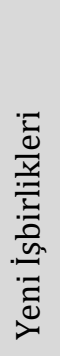 & 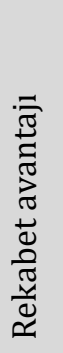 & 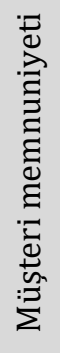 & 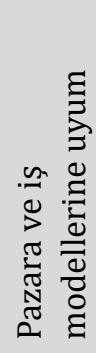 \\
\hline $\begin{array}{lr}\text { Wirtz \& } \\
\text { Daiser, } 2017\end{array}$ & $\mathrm{X}$ & $\mathrm{X}$ & & & & & & $\mathrm{X}$ & & $\mathrm{X}$ & $\mathrm{X}$ & $\mathrm{X}$ \\
\hline $\begin{array}{l}\text { Anderson \& } \\
\text { Kupp, } 2008\end{array}$ & & & & & & & $\mathrm{X}$ & & $\mathrm{X}$ & $\mathrm{X}$ & & \\
\hline $\begin{array}{l}\text { Chesbrough, } \\
2010\end{array}$ & & & & & $\mathrm{X}$ & & & & & & & \\
\hline $\begin{array}{l}\text { Burmeister } \\
\text { vd., } 2016\end{array}$ & $\mathrm{X}$ & & & $\mathrm{X}$ & & & & & & & $\mathrm{X}$ & \\
\hline $\begin{array}{l}\text { de Reuver \& } \\
\text { Bouwman, } \\
2009\end{array}$ & $\mathrm{X}$ & & & & & $\mathrm{X}$ & & & & & & $\mathrm{X}$ \\
\hline Ezeokli, 2016 & & & & $\mathrm{X}$ & & $\mathrm{X}$ & $\mathrm{X}$ & & & $\mathrm{X}$ & $\mathrm{X}$ & $\mathrm{X}$ \\
\hline $\begin{array}{ll}\text { Kane } & \text { vd., } \\
2015 & \end{array}$ & $\mathrm{X}$ & $\mathrm{X}$ & $\mathrm{X}$ & & & & & & & & & \\
\hline $\begin{array}{l}\text { Morakanyane } \\
\text { vd., } 2017\end{array}$ & $\mathrm{X}$ & $\mathrm{X}$ & $\mathrm{X}$ & & & & & & & & & $\mathrm{X}$ \\
\hline $\begin{array}{l}\text { Verina \& } \\
\text { Titko, } 2019\end{array}$ & $\mathrm{X}$ & & & $\mathrm{X}$ & $\mathrm{X}$ & & & & $\mathrm{X}$ & & $\mathrm{X}$ & $\mathrm{X}$ \\
\hline $\begin{array}{l}\text { Tesch \& } \\
\text { Brillinger, } \\
2017\end{array}$ & $\mathrm{X}$ & & & & & & & & & $\mathrm{X}$ & & $\mathrm{X}$ \\
\hline Kofler, 2018 & $\mathrm{X}$ & & & & & & & & & $\mathrm{X}$ & $\mathrm{X}$ & $\mathrm{X}$ \\
\hline $\begin{array}{l}\text { Pflaum \& } \\
\text { Schulz, } 2017\end{array}$ & $\mathrm{X}$ & & $\mathrm{X}$ & & & & & & & & & \\
\hline $\begin{array}{l}\text { Foss \& Saebi, } \\
2017\end{array}$ & $\mathrm{X}$ & $\mathrm{X}$ & $\mathrm{X}$ & & & & & & & $\mathrm{X}$ & & \\
\hline
\end{tabular}




\begin{tabular}{|l|c|c|c|c|c|c|c|c|c|c|c|c|}
\hline $\begin{array}{l}\text { Liere- } \\
\text { Netheler vd., } \\
2018\end{array}$ & & & & $\mathrm{X}$ & $\mathrm{X}$ & $\mathrm{X}$ & $\mathrm{X}$ & $\mathrm{X}$ & & & $\mathrm{X}$ & $\mathrm{X}$ \\
\hline $\begin{array}{l}\text { Chanias, } \\
2017\end{array}$ & $\mathrm{X}$ & & $\mathrm{X}$ & & & $\mathrm{X}$ & & & & & $\mathrm{X}$ & \\
\hline $\begin{array}{l}\text { Tesch \& } \\
\text { Brillinger, } \\
2017\end{array}$ & $\mathrm{X}$ & & & & & & & & & $\mathrm{X}$ & & $\mathrm{X}$ \\
\hline
\end{tabular}

\section{Kaynak: Yazar}

Tespit edilen etmenlerin arasındaki sebep-sonuç veya kapsam gibi ilişkiler dikkate alınarak etmenler Şekil 4'te gösterildiği gibi gruplandırılmışlardır. Buna göre dijital teknoloji ve dijital yetkinlik etmenleri dijital dönüşümün ana etmenleridir. Dijital teknolojiler ve yetkinliklerin varlığı hem işletmeleri hem de işletmelerin yer aldığı tüm pazarı dijitalleștirir. İşletmelerdeki dijital dönüşüm, ya işletmenin içerisinden yönetimin dijital teknolojileri kullanma konusunda aldığı kararlar ve koyduğu hedefler doğrultusunda ya da işletmelerin dijital teknolojilerin etkisiyle değişen yeni pazar şartlarına uyum sağlamak isteğiyle olur. Buna dayanarak Tablo 1'deki tüm etmenler dijital teknoloji/dijital yetkinlik, yönetim ve pazar etmenleri başlıkları altında üç etmen grubunda toplanir:

- Dijital Teknoloji/Yetkinlik: Dijital teknolojilerin ortaya çıkması ve toplumda dijital yetkinliklerin artması hem işletme yönetimini hem de pazar şartlarını ve ortamını değiştirmekte ve dijitalleștirmektedir. Tablo 1'deki "dijital teknoloji" ve "dijital yetkinlik" etmenleri bu gruba dahildir.
- İşletme Yönetimi: İşletme Yönetimi etmenleri işletmede üst yönetimin dijitalleşme konusunda

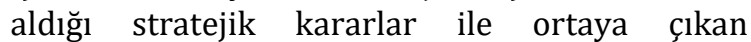
etmenlerdir. Üst yönetimin dijital teknolojileri kullanma yönünde stratejik kararlar almasının sebepleri işlevsel iyileştirme (Dijital İşlev), iş değer zincirinde üretimden gelen değişiklikler (Dijital İş Değer Zinciri) ve kâr ve gelir artışıdır (Dijital Gelir). İşletme Yönetimi başlığı Tablo 1'deki "stratejik karar" ve "üst yönetim" etmenlerini kapsamakta olduğundan bu iki etmen ayrica ele alınmaz.

- Pazar: Pazar etmenleri ișletmeleri dijital dönüşümünü tetikleyen diğer etmen grubudur. Pazar etmenleri dijitalleşme sonucu pazarda süregelen yeni rekabet ortamı (Dijital Rekabet), yeni müşteri ihtiyaçları ve beklentileri (Dijital Müşteri), pazarın yeni şartlarına, pazarda oluşan yeni iş modellerine ve bu bağlamda doğan yeni ekosistemlerdeki işbirliklerine uyum (Dijital İş Modelleri) ve devletin uygulamaya geçirdiği dijitalleşme mevzuatlarıdır (Dijital Mevzuat).

Şekil 3. Dijital Dönüşüm Etmen Grupları

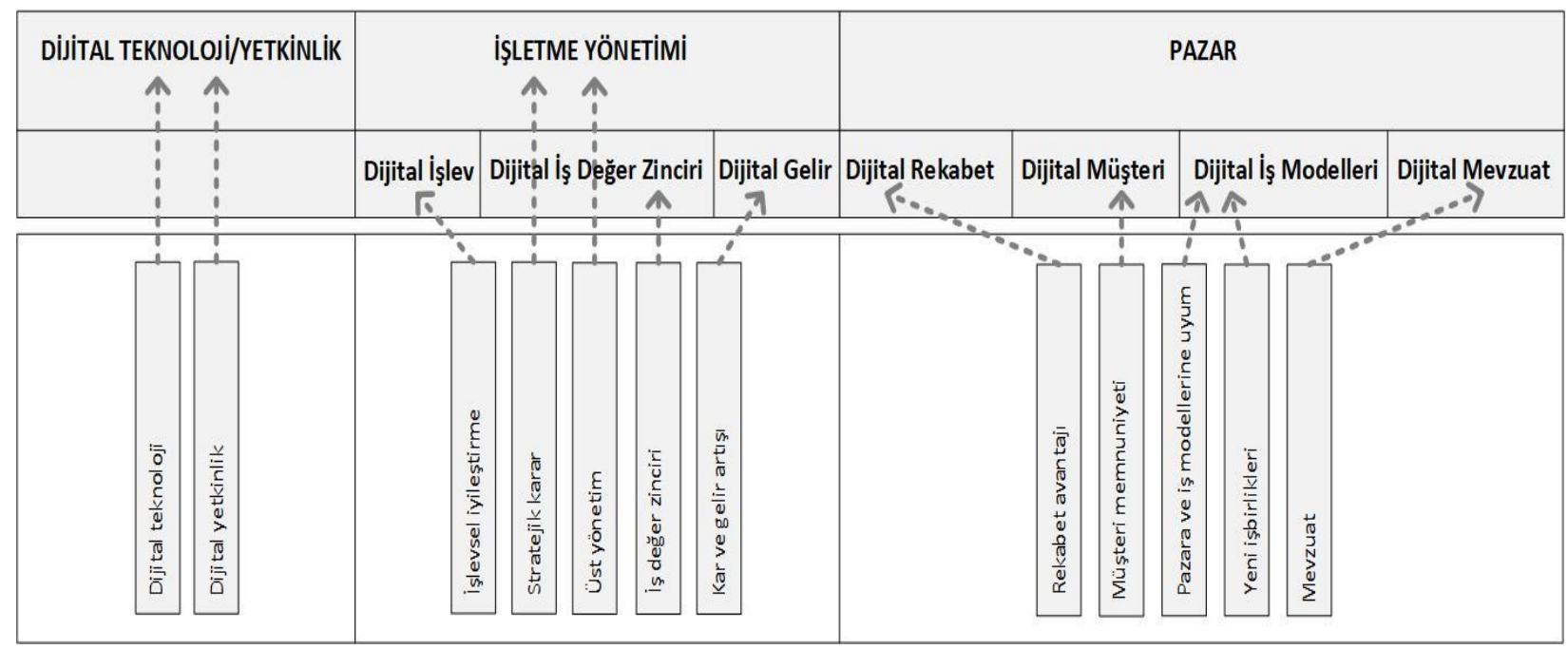

Kaynak: Yazar 


\section{4 | DİIITAL DÖNÜŞÜM NEDENSEL İLİŞKİ MODELİ}

Dijital dönüșüm ve etmenleri hakkındaki nedensel model, ilişkiler diyagramı kullanılarak geliştirilmiştir. İlişkiler diyagramı bir grup fikir arasındaki itici güçler ve sonuçlarının arasındaki bağlantıyı göstermekte kullanılan grafiksel bir yöntemdir ve karmaşık durumların çözülmesinde neden-sonuç ilișkilerini modelleyerek destek olur (Mut, 2018). İlişkiler diyagramında kavramlar arasında kullanılan okların yönü sebep-sonuç ilişkisini ifade eder.

İșletmelerdeki dijital dönüșüm için ilișkiler diyagramı ile bir nedensel model geliştirilirken ilk belirlenmesi gereken nokta işletmelerde nelerin dönüşüme uğrayacağı (SONUÇ) ve bu dönüşümü tetikleyen etmenlerin (NEDEN) neler olduğudur. Yukarıdaki bölümde İşletme 4.0 bașlığı altında işletme içerisinde dönüșüm yașanacağı alanlar "İș Model Dönüșümü", "Organizasyon Dönüşümü" ve "İş Süreç Dönüşümü" olarak, etmenler ise "Dijital Teknolojiler/Yetkinlikler", "İşletme Yönetimi" ve "Pazar" şeklinde belirlenmiştir.

İlişkiler diyagramı oluşturmakta yapılacak ikinci adım, etmenlerin ve alanların kendi içlerinde ve birbirleri arasındaki ilișkileri belirlemektir. Etmenlerin kendi aralarındaki ilișkiler incelendiğinde "Dijital Teknolojiler/Yetkinlikler" etmeninin diğer iki etmenin tetikleyicisi olduğu ve onları etkilediği görülmektedir. Dijital teknolojilerin gelişmesi ve dijital yetkinliklerin oluşması hem işletme yönetimi hem de pazarı dijital dönüșüme itmektedir. Dönüşüm alanları arasındaki ilişkiyi belirlerken ortaya şu soru çıkar: İşletmenin yönetim kararıyla iş modellerini değiştirmesi veya pazarda oluşan yeni iş modellerine katılması mı işletmenin iş süreçlerinde ve organizasyonunda dönüșüm ve değișime mi yol açar? Yoksa teknoloji kullanımıyla değișen iş süreçleri ve yeni organizasyon mu işletmenin iş modellerini dönüștürür? Aslında her ikisi de mümkündür. İşletmenin dönüşüm alanları arasında bir döngü vardır. Hem dijital teknolojiler ve yetkinlikler sayesinde mümkün olan yeni iş modelleri işletmede iş süreçlerinin ve bununla beraber organizasyon yapısının değişmesine yol açar hem de yeni teknolojileri üretimde veya müşteri ilişkileri yönetiminde kullanan şirketlerde bunun sonucunda iş süreçlerini ve organizasyon yapısını değiștirecek yeni iş modelleri ortaya çıkar (Hess vd., 2016).

Șekil 5'te dijital dönüșüm etmenleri ve alanları arasındaki ilişkiler dikkate alınarak oluşturulan nedensel model yer almaktadır. Dijital Teknoloji/Yetkinlik etmeni İşletme Yönetimi ve Pazar etmenlerini tetikler. Pazar etmenleri işletmeleri iş modellerin dönüşümüne sebep olurken, işletme yönetimi etmenleri doğrudan iş süreçlerini değiștirmeyi tetikleyebildiği gibi iş modellerinin de dönüşümüne yol açar. Değişen iş modelleri işletmenin iş süreçlerinde dönüşüm yaratır. İş süreçlerindeki dönüşüm organizasyondaki dönüşüme sebebiyet verir.

Şekil 4. İşletme 4.0 - Dijital Dönüşüm Nedensel Modeli - İlişki Diyagramı

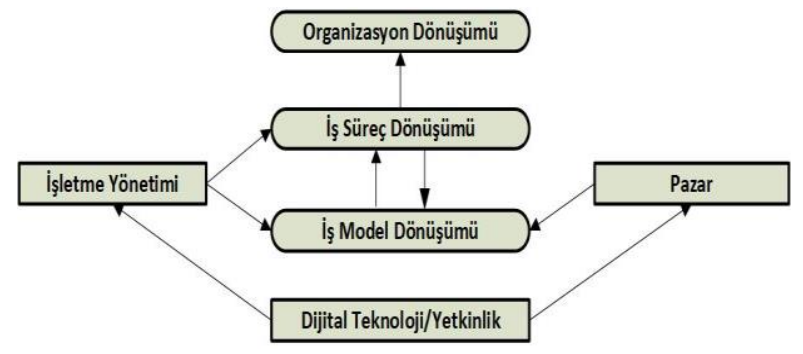

Kaynak: Yazar

Dijital dönüşüm etmenlerinin alt başlıkları ve onların dönüşüm alanlarıyla olan ilişkileri dikkate alınarak genişletilmiş nedensel model oluşturulmuştur (Şekil 6). İşletme yönetimi üç etmen grubundan oluşur (Şekil 4): Dijital İşlev, Dijital İş Değer Zinciri ve Dijital Gelir. Dijital İşlev, işletmedeki dijital teknolojilerin, işletmedeki tüm işlevlerin iyileştirilmesi amaciyla kullanılmasını ifade eder. Dijital teknolojilerin işlev iyileştirilmesi için kullanılması işletmelerde iş süreç dönüșümüne yola açar. İș süreçlerinde yapılan değişiklikler organizasyon değişikliklerine yol açar ve aynı zamanda yeni iş modellerini de beraberinde getirebilir. Dijital İş Değer Zinciri işletmelerde Endüstri 4.0 ile akıllı fabrikalara geçişle ortaya çıkan bir etmendir. Yukarıdaki bölümde bahsedilen yatay ve dikey entegrasyon işletmenin tedarik zinciri üzerindeki tüm paydaşları ve işletmenin fonksiyonlarını birbiriyle birleştirir. Bunun sonucunda bir yandan iş süreçleri dönüşür, diğer yandan da tedarik zincirinin farklı aşamalarında yeni iş modelleri ortaya çıkar. Kısacası bu etmen hem iş süreç dönüşümü hem de iş model dönüşümü alanlarını tetikler. Dijital Gelir, işletmelerin dijital teknolojileri ve yetkinlikleri kullanarak yeni gelir artış olanakları oluşturmak istemelerini ifade eden etmendir. Bu da yeni iş modelleri oluşmasına sebep olur. Yeni iş modelleri iş süreçlerini dönüştürür, değişen iş süreçleri yeni organizasyon yapısını beraberinde getirir.

Pazar etmenleri dört başlık altında toplanır (Şekil 4): Dijital Rekabet, Dijital Müşteri, Dijital İş Modelleri ve Dijital Mevzuat. Pazar etmenlerinin tümü iş model dönüşümünü tetikler. Pazarda dijital dönüşüm sonucu oluşan yeni rekabet ortamında (Dijital Rekabet) işletmeler avantaj elde etmek isterler ve bu onları yeni iş modelleri geliştirmeye yöneltir. Değișen müşteri talep ve ihtiyaçları (Dijital Müşteri) farklı bir müşteri ilişkileri yönetimi gerektirir ve işletmeleri yeni iş modelleri geliştirmeye yöneltir. Üçüncü olarak pazarda yeni oluşmuş iş modelleri (Dijital İş Modelleri), özellikle farklı işletmelerin farklı rollerde 
katıldıkları ekosistemler, işletmeleri işbirliği yapmaya özendirir ve bunun için yeni iş modelleri geliştirmeye teşvik eder. Ve en son olarak da devlet tarafından dijitalleşme ve dijital iş konusunda yapılan yeni düzenlemeler (Dijital Mevzuat), işletmelerin iş modellerini dönüştürmelerini kolaylaştırır ve yeni iş modellerine sebebiyet verirler. Pazar etmenlerinin sebep verdiği iş model dönüşümü işletmenin süreçlerini ve daha sonra organizasyonunu etkiler.

Şekil 5. İşletme 4.0 - Dijital Dönüşüm Nedensel Modeli - İlişki Diyagramı (genişletilmiş)

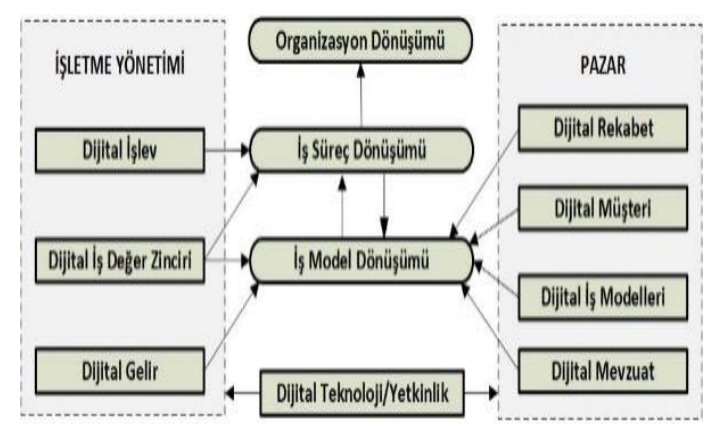

Kaynak: Yazar

\section{5 | SONUC}

Dijital dönüşüm hakkında uluslararası alanda yürütülmüş geniş kapsamlı bir araştırma, işletmelerin dijital dönüşüme verdikleri önemi vurgularken, incelenen işletmelerin dörtte üçünün dijital dönüșüm yolculuğunda olduğunu ve bunların da üçte ikisi gibi bir çoğunluğunun dijital dönüşümün zorlayıcı olduğunu düşündüklerini göstermektedir (Oswald \& Krcmar, 2018). Bu zorlu görevi başarıyla tamamlamak için işletmeyle uyum içinde bir dijital dönüşüm stratejisi gereklidir. İşletmelerdeki dijital dönüşümün birçok farklı alanı ve boyutu vardır. Doğru dijital dönüşüm stratejisi geliştirmek için dönüşümü tetikleyen etmenlerin kendi aralarındaki ve bunların dönüşüm alanlarıyla olan ilişkileri belirlenmelidir. Mevcut kaynaklarda her ne kadar dijital dönüşümden bahsedilse, alanları belirlense ve etmenleri araştırılsa da aralarındaki bağlantı incelenmemektedir. $\mathrm{Bu}$ çalışma, akademik literatürdeki bu eksikliği doldurmak ve işletmelere dijital dönüşüm yol haritası çizerken yardımcı olmak amacıyla işletmelerdeki dijital dönüşüm alanlarını dijital dönüşüm etmenleriyle ilişkilendirmiştir.

Bu çalıșma "İșletme 4.0 - Dijital Dönüșüm Kavramsal Çerçevesi" araştırma projesinin bir bölümüdür. Bundan sonraki aşamada bu çalışmanın sonucu olan Dijital Dönüşüm Nedensel Model'inde gösterilen neden-sonuç ilişkilerinin doğruluğu işletmelerde dijital dönüşüm etmenleri hakkında yürütülecek bir anket çalışmasıyla sorgulanacak ve gerekirse model revize edilecektir. Bu çalışmadan da görüldüğü gibi farklı etmenler işletmelerde farklı dijital dönüşüm senaryolarına yol açmaktadır. Buna dayanarak kavramsal çerçevenin ikinci bölümünde işletmeler için farklı dijital dönüşüm senaryoları belirlenecek ve daha sonra farklı senaryolar için birbiriyle uyumlu dijital dönüşüm stratejileri geliştirilecektir.

\section{KAYNAKÇA}

Akben, İ. \& Avşar, Ö.G.İ.I. (2017). Dijital tedarik zinciri ve bulut bilișim. El-Ruha: 104.

Anderson, J. \& Kupp, M. (2008). Serving the poor: Drivers of business model innovation in mobile. Info, 10(1): 5-12.

Bächle, M. A. (2016). Wissensmanagement mit Social Media. Berlin/Boston: Walter de Gruyter.

Banger, G. (2018). Endüstri 4.0 Ekstra. Ankara: Dorlion.

Berghaus, S. \& Back, A. (2016). Gestaltungsbereiche der digitalen Transformation von Unternehmen: Entwicklung eines Reifegradmodells. Die Unternehmung, 70(2): 98-123.

Besson, P. \& Rowe, F. (2012). Strategizing information systems-enabled organizational transformation: A transdisciplinary review and new directions. The Journal of Strategic Information Systems, 21(2): 103-124.

Blunck, E. \& Werthmann, H. (2017). Industry 4.0 - An opportunity to realize sustainable manufacturing and its potential for a circular economy. In DIEM: Dubrovnik International Economic Meeting, 3(1): 644-666.

Burmeister, C., Lüttgens, D. \& Piller, F. T. (2016). Business model innovation for Industrie 4.0: Why the "Industrial Internet" mandates a new perspective on innovation. Die Unternehmung, 70(2): 124-152.

Chanias, S. (2017). Mastering digital transformation: The path of a financial services provider towards a digital transformation strategy. Proceedings of the 25th European Conference on Information Systems (ECIS), Guimarães, Portugal.

Chesbrough, H. (2010). Business model innovation: opportunities and barriers. Long range planning, 43(2-3): 354-363.

De Reuver, M., Bouwman, H. \& MacInnes, I. (2009). Business models dynamics for start-ups and innovating e-businesses. International Journal of Electronic Business, 7(3): 269-286.

Ehret, M. \& Wirtz, J. (2017). Unlocking value from machines: Business models and the industrial internet of things. Journal of Marketing Management, 33(1-2): 111-130. 
Ezeokoli, F. O., Okolie, K. C., Okoye, P. U. \& Belonwu, C. C. (2016). Digital transformation in the Nigeria construction industry: The professionals' view. World Journal of Computer Application and Technology, 4(3): 23-30.

Fitzgerald, M., Kruschwitz, N., Bonnet, D. \& Welch, M. (2014). Embracing digital technology: A new strategic imperative. MIT sloan management review, 55(2): 1 .

Fleisch, E., Weinberger, M. \& Wortmann, F. (2015). Geschäftsmodelle im Internet der Dinge. Schmalenbachs Zeitschrift für betriebswirtschaftliche Forschung, 67(4): 444-465.

Foss, N. J., \& Saebi, T. (2017). Fifteen years of research on business model innovation: How far have we come, and where should we go? Journal of Management, 43(1): 200-227.

Henriette, E., Feki, M. \& Boughzala, I. (2016). Digital Transformation Challenges. Proceedings Mediterranean Conference on Information Systems (MCIS): 33.

Hess, T., Matt, C., Benlian, A. \& Wiesböck, F. (2016). Options for formulating a digital transformation strategy. MIS Quarterly Executive, 15(2).

Kane, G. C., Palmer, D., Phillips, A. N., Kiron, D. \& Buckley, N. (2015). Strategy, not technology, drives digital transformation. MIT Sloan Management Review and Deloitte University Press, 14: 1-25.

Klein, M. (2019a). Geniş Kapsamlı Dijital Dönüşüm Yaklaşımı - Dünya 4.0. E.S. Bayrak Meydanoğlu, M. Klein \& D. Kurt (Eds.), Dijital Dönüşüm Trendleri, Filiz.

Klein, M. (2019b). İşletme 4.0 Kapsamında Şirket 2.0 - İşletme Süreçlerinde Sosyal Yazılım Kullanımı. İstanbul: Nobel Akademik Yayıncllık.

Klein, M. (2020). Leadership characteristics in the era of digital transformation. Business \& Management Studies: An International Journal, 8(1): 883-902.

Kress, P., Löwen, U. \& Pflaum, A. (2017). A role model of production value networks. AtAutomatisierungstechnik, 65(1): 19-25.

Kofler, T. (2018). Digitale Transformation in Unternehmen. Zentrum Digitalisierung Bayern Positionspapier.

http://www.steinbeis-

be.de/fileadmin/user_upload/Digitalisierung_Bayer n.pdf (Erişim: Nisan, 2020).

Liang, T. P. \& Turban, E. (2011). Introduction to the special issue social commerce: a research framework for social commerce. International Journal of Electronic Commerce, 16(2): 5-14.
Liere-Netheler, K., Packmohr, S. \& Vogelsang, K. (2018). Drivers of Digital Transformation in Manufacturing. Proceedings of the 51st Hawaii International Conference on System Sciences: 3926 3935.

Markides, C. (2006). Disruptive innovation: In need of better theory. Journal of Product Innovation Management, 23(1): 19-25.

Matt, C., Hess, T. \& Benlian, A. (2015). Digital transformation strategies. Business \& Information Systems Engineering, 57(5): 339-343.

Matyssek, T. (2017). Geschäftsmodelle im Internet der Dinge. In D. Schallmo, A. Rusnjak, J. Anzengruber, T. Werani \& M. Jünger (eds.), Digitale Transformation von Geschäftsmodellen. Wiesbaden: Springer Gabler: 159 - 178.

Morakanyane, R., Grace, A. A. \& O'Reilly, P. (2017). Conceptualizing digital transformation in business organizations: A systematic review of literature. In Bled eConference: 21.

Mut, G. B. (2018). Problem çözmede 7 araç. http://www.gbmut.com/problem-cozmede-7-arac/ (Erişim: Ekim 2019).

Osterwalder, A., Pigneur, Y., Oliveira, M. A. Y. \& Ferreira, J. J. P. (2011). Business Model Generation: A handbook for visionaries, game changers and challengers. African journal of business management, 5(7): 22-30.

Oswald, G. \& Krcmar, H. (Eds.). (2018). Digitale Transformation: Fallbeispiele und Branchenanalysen. Springer-Verlag.

Özdoğan, O. (2017). Endüstri 4.0: Dördüncü Sanayi Devrimi ve Endüstriyel Dönüşümün Anahtarları. Pusula.

Peltoniemi, M. \& Vuori, E. (2004). Business ecosystem as the new approach to complex adaptive business environments. Proceedings of eBusiness research forum, 2: 267-281.

Porter, M. E. (2001). The value chain and competitive advantage. Understanding Business Processes: 50-66.

Pflaum, A. \& Schulz, E. (2018). Auf dem Weg zum digitalen Geschäftsmodell. HMD Praxis der Wirtschaftsinformatik, 55(2): 234-251.

Schwab, K. (2017). The Fourth Industrial Revolution. Portfolio Penguin.

Sezgin Koyun (2019). İşletme Analizi Nedir? İş Analizi ve Finansal Analiz. https://www.sezginkoyun.com/isletme-analizi/\# (Erişim: Nisan 2020)

Staffen, S. \& Schoenwald, L. (2016). Leading in the Context of the Industrial Revolution. Capgemini. https://www.capgemini.com/consulting-de/wp- 
content/uploads/sites/32/2017/08/resouces_leade r_40_industrial_revolution.pdf (Erişim: Nisan 2020).

Tesch, J. \& Brillinger, A. (2017). The evaluation aspect of digital business model innovation: A literature review on tools and methodologies. Proceedings of the 25th European Conference on Information Systems (ECIS), Guimarães, Portugal: 2250-2268.

Veit, D., Clemons, E., Benlian, A., Buxmann, P., Hess, T., Kundisch, D., ... \& Spann, M. (2014). Business models. Business \& Information Systems Engineering, 6(1): 45-53.

Verina, N., \& Titko, J. (2019). Digital transformation: conceptual framework. International Scientific Conference Contemproray Issues in Business, Management and Economics Engineering, VGTU Press.

Westerman, G., Calméjane, C., Bonnet, D., Ferraris, P. \& McAfee, A. (2011). Digital Transformation: A roadmap for billion-dollar organizations. MIT Center for Digital Business and Capgemini Consulting, 1: 168.

Wigand, R. T. (1997). Electronic commerce: Definition, theory, and context. The information society, 13(1): 1-16.

Wirtz, B., \& Daiser, P. (2017). Business model innovation: An integrative conceptual framework. Journal of Business Models, 5(1). 